\title{
HeLPing Engineers DeVelop AND EXercise CREATIVE MUSCLES
}

\author{
Zbigniew J. Pasek \\ University of Windsor \\ zjpasek@uwindsor.ca
}

\begin{abstract}
A recent IBM-conducted survey of CEOs of multinational corporations indicated that creativity trumps other leadership characteristics. Across industries, organizations operate in increasingly complex and uncertain environments. Existing solutions are quickly exhausted or become obsolete, thus replacing them requires continuous innovation. Teaching existing solutions, the mainstay of formal education, is not enough. Students must learn how to consciously frame and reframe problems, create new knowledge and generate creative solutions on an ongoing basis. Most important, students must learn ways to motivate themselves to recognize and seek out problems as opportunities for generating creative solutions.

While in higher education importance of creativity is recognized, practical implementation of teaching it is still an afterthought or a sideline. While creativity as an academic subject is somewhat elusive, in particular in engineering education, recent accumulation of knowledge enables implementation of more systematic approaches.
\end{abstract}

Keywords: Creativity, Creative problem solving, Metacognition, Design thinking.

\section{INTRODUCTION}

A recent IBM-conducted survey of CEOs of multinational corporations indicated that creativity trumps other leadership characteristics. Across industries, organizations operate in increasingly complex and uncertain environments. Existing solutions are quickly exhausted or become obsolete, thus replacing them requires continuous innovation. Teaching existing solutions, the mainstay of formal education, is not enough. Students must learn how to consciously frame and reframe problems, create new knowledge and generate creative solutions on an ongoing basis. Most important, students must learn ways to motivate themselves to recognize and seek out problems as opportunities for generating creative solutions.
A provocative paradox in higher education is that we want students to be creative, but do not teach them how to be creative other that doing brainstorming. Similarly, we want students to be leaders or team players, but we spend little time and energy helping them develop such skills.

\section{CREATIVITY LEVELS}

The initial difficulty in teaching students to think creatively is overcoming their fear of too high expectations from their efforts. Many models explaining various aspects of creativity exist, but most of them are trying to explain it on a holistic way, thus making it difficult to manage in the mind of a student.

One of the models that avoids these pitfall is a Levelsof-Creativity approach, introduced by Jeff De Graf [1]. According to that model, there are five levels of creativity that happen in different ways and are tied to increasing levels of complexity:

- Mimetic

- Bisociative

- Analogical

- Narratological

- Transcendental.

The most basic level is called the mimetic and that means to imitate. That is a great entry point to the field of creation, hinting that the easiest way to create is you imitate somebody else (which, by the way, is practiced by many artists who readily admit that they were inspired by somebody else's work).

The second level is called by bisociative. This is why brainstorming works: you combine two ideas an idea that you are already familiar with with an idea that you are not familiar with and together they give birth to a new idea.

The third level is called an analogical and that means one is making an analogy or a metaphor, or in the other words tries to explain something new by making a comparison to something already known. What analogies and metaphors do is they cluster ideas together and resulting outcomes are either ideas that we are familiar with that we want to make unfamiliar or defamiliarize or there are ideas that were unfamiliar with and we want to 
make familiar. For example, someone might say "drinking this new soda is like jumping into a cold swimming pool on a hot day," and that immediately creates the connection with something familiar.

The fourth level is the narratological, and that's our ability to tell stories. Stories have a lot of characters and a various plots, and a lot of settings and other details that are involved. Stories that are compelling are complex, but it is essential that they be rich in detail. It requires a lot of effort to put together a good story, but this is paramount when conveying a complicated solution or a strategy which is, in essence, an involved story.

The highest level of creativity is called transcendental or the intuitive level. At this level the creativity is perhaps happening in a way that is neither rational nor cognitive. At this level people believe they are getting inspiration from an outside source. However, to access this kind of creativity one may need, for example, to learn to meditate to elevate oneself to higher level of consciousness that would leave the rational thinking behind.

\section{CREATIVE PROCESS}

Path of the creative process takes a diamond shape [3]. At the start there is a need to be highly divergent. That means a lot of ideas should be generated with very little (or no) judgment. The intent is to focus on quantity rather than quality, and to include even strange ideas. These outof-the-ordinary ideas are important because they are eventually creating points of departure for further discussion. It is also important not only to talk but also to draw and to use hand gestures, and maybe even act things out. It is also worth to build (crude) prototypes. Overall, the goal is to create a great width of ideas.

The second part of the creative process is to converge and this means that from this great width, one has to select the best ideas and to be successful, one has has to employ judgment. To be rationally judgmental, there have to be criteria defined and deployed. These may include, for example, feasibility, time, and cost.

The key issue is to never start the creative process from convergence (e.g., knowing what the "right" solution may be ahead of the creative deliberation) because what that does it limit the range of creative ideas that are available. In other words, it will make them incremental and ordinary. So first, the participants have to be allowed to go little bit crazy before one can decide which ideas are really best suited to create a winning solution.

According to neuroscience, human brains are naturally creative when introduced to new information. Two things happen: (i) it can assimilate this new information into the structures that it already has, and (ii) it can also accommodate new information by building new structures.
One of the ways in which the human brain can be forced into being creative is called defamiliarization. All that has to be done is to present the known idea in a known setting and then connect it to an unknown idea. That can be accomplished in a few different ways.

One is forced randomization. Take an idea and open any book on any page and point to a word and the random connection would create an opportunity to brainstorm how these two words might go together. The other way is to have a preset formal list of words and simply take an idea and try and connect it to some of the words on that list; this will generate a whole series of new ideas.

Another way to connect random words is to organize words by certain types of activities. In the 1950s Alex Osborne, an advertising executive, came up with an acronym for a simple mnemonic device to remember how to connect your idea to an action-oriented idea and he called this SCAMPER. For those formalism-oriented, the words can be called action operators; the following actions are defined:

- Substitute

- Combine

- Adapt

- Modify (Minify or Magnify)

- Put to another use

- Eliminate

- Reverse.

To scamper all one has to do is take the idea and ask what would happen if one applied this action on the idea. By scampering one can take a familiar idea, add action to it and voila! A whole range of new ideas is generated.

One of the functions of our mind is to make metaphors and analogies and what metaphors and analogies do is they connect things that we're familiar with two things that were unfamiliar with. The Greeks called this synthetic thinking.

Now, in order to make creativity work with synthetic thinking we have to take a few steps. First, we have to identify a challenge or an opportunity and we have to get below the challenge or the opportunity to what's really making it a challenge or an opportunity. In industry people often call it the root cause.

The final step in creative problem solving is to take these newly-generated ideas and combine them into a solution. But with many creative ideas, how to decide their worth? Typically, the ideas can fall into one of four categories (see Fig. 1). Each of those categories may offer a different payback value and also have different level of difficulty with regards to its implementation. Also, in each category the difficulty of generating useful ideas may differ; thus in some case most desired ideas may not be coming in large numbers. 


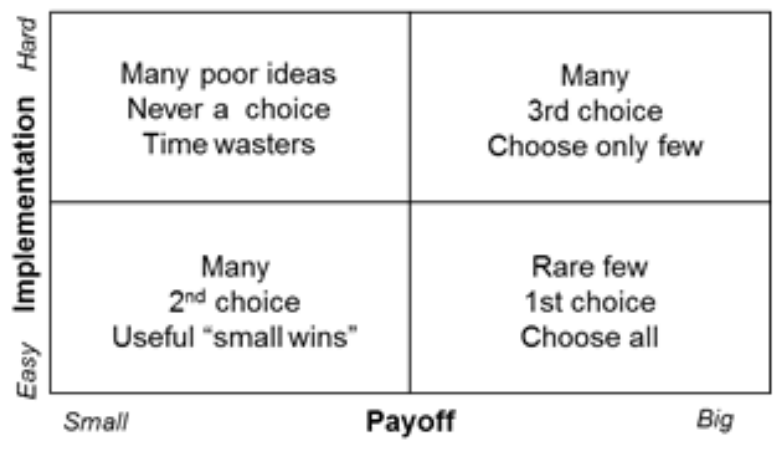

Figure $X$. Selection rules of ideas

\section{CREATIVITY FOR ENGINEERS}

The experiences discussed here are related to development and teaching of a graduate-level Creative Problem Solving course for engineers. This course offers the student an opportunity to discover and use their creative potential to produce solutions to challenging engineering and non-engineering problems. Students learn how to employ effective methods, tools and techniques that maximize creative output while working with both individually and in groups and master divergent and convergent thinking processes. They also learn strategic creative problem solving models that systematize their approach to problem solving and innovative thinking. The knowledge, skills and attitudes supporting self-directed creative problem solving include creative metacognition, paradoxical frame making and a willingness to engage in integrative thinking, i.e. the ability to hold conflicting ideas when thinking about problems and generating solutions $[5,6,7]$.

One of the crucial elements students develop in the course is metacognition (e.g. thinking about thinking), or awareness of their own thinking processes. Such a selfdiscovery challenges educators to help students become knowledgeable about their cognitive processes (declarative, procedural, conditional knowledge), and how to regulate them (plan, monitor, evaluate) in order to learn, make decisions, solve problems, generate ideas and perform other cognitive tasks. Creative metacognition focuses on cognitive tasks that involve generating, choosing and evaluating creative ideas and then apply those ideas to develop products and services, new solutions to problems and other innovative tasks.

Most of these concepts and related skills can be relatively easily ported into the Design Thinking (DH) approach framework, and more specifically Human Centered Design (HCD), a variant of Design Thinking. Within the context of HCD projects, students encounter problematic situations that expose conflicting, paradoxical demands (these are often referred to as wicked problems).

In an engineering creative problem solving course, creative thinking techniques were introduced and practiced in order to encourage students to consciously and deliberately apply them both course related projects and in their personal challenges. A semester-long class project discussed throughout the class was an issue of food waste and possible solution to it reduction, if not complete elimination

Metacognition involves being aware of one's thought process. It begins by gaining understanding of thought processes like, for example, decision making and exerting conscious control over them to generate ideas, make decisions, develop strategies, etc. Creative metacognition focuses on skills and processes that generate ideas, and solve problems.

Creative thinking and creative metacognition can be taught. It involves explicit teaching of creative thinking strategies as processes like, for example, mind mapping, lateral thinking or problem framing; and reinforcing that learning through practice and reflection. Students learn both how to think, and how to steer their thinking towards creative behaviour. Over time, and with sufficient formative assessment, students develop creative metacognition skills, which combine not only knowledge how to create, but also when, where, and how, to be creative.

The challenge for educators is that course curricula are already crowded and expecting faculty to teach creativity and metacognition, in addition to discipline-specific content, is a losing proposition. Few faculty members will find the time to teach students creative thinking strategies without good reason [2].

Our experience with classroom use of Human Centered Design (HCD), a variant of Design Thinking, indicates that students can effectively acquire understanding and apply creative thinking with creative metacognition strategies while learning discipline specific knowledge.

Within the context of HCD projects, students are facing problematic situations, but through analysis are able to expose conflicting, paradoxical demands. They must overcome the tendency to engage in binary (either/or) thinking and instead take a different path to generate alternative ideas, solutions, and experiences for the end user, that resolve initially contrary demands.

In doing that, they must learn how to create problem spaces containing conflicting demands (e.g., the virtual space between an existing and a desired state). Human Centered Design establishes that space during the Inspiration phase where a problematic situation is fully explored from the perspective of the end user of the designed solution. When paradoxes and contradictions emerge, students learn to value them as opportunities to 
produce robust and powerful solutions for their end users/clients.

\section{A FEW CREATIVE EXERCISE EXAMPLES}

A number of creative activity exercises, which seem to be particularly well suited for engineering students.

\subsection{Circles Exercise}

This is an excellent warm-up exercise. Originally introduced in [4], with detailed instructions and guidance for discussion. Simple in execution as only a sheet of paper with 30 blank circles and a pencil are needed Recommended and sufficient duration is $90 \mathrm{~s}$ per single run; two runs can be conducted at the beginning and the end of class to show improvement.

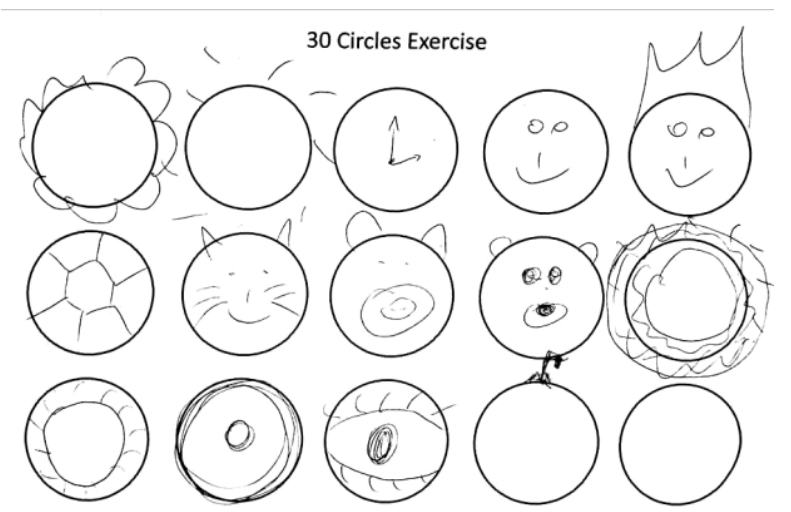

Figure 2. Result of 30 Circles exercise

\subsection{Spaghetti Tower (aka Marshmallow Challenge)}

Great team exercise, to which engineering students respond particularly well, even though they not always perform well. Originally introduced by Tom Wujec [9] and proliferated across multiple levels of education, from kindergarten through college. The task is simple: in eighteen minutes, teams must build the tallest freestanding structure out of 20 sticks of spaghetti, one yard of tape, one yard of string, and one marshmallow. The marshmallow needs to be on top. The time to complete the challenge is 18 mins.

Often times students overthink their designs and do not want to try any risky solutions, they do not want to experiment. They are also often surprised by the ability of spaghetti to withstand fair amount of load before breaking. Another surprise is also the (big) weight of the marshmallow and what effect is has on their design, which usually sway and bend.

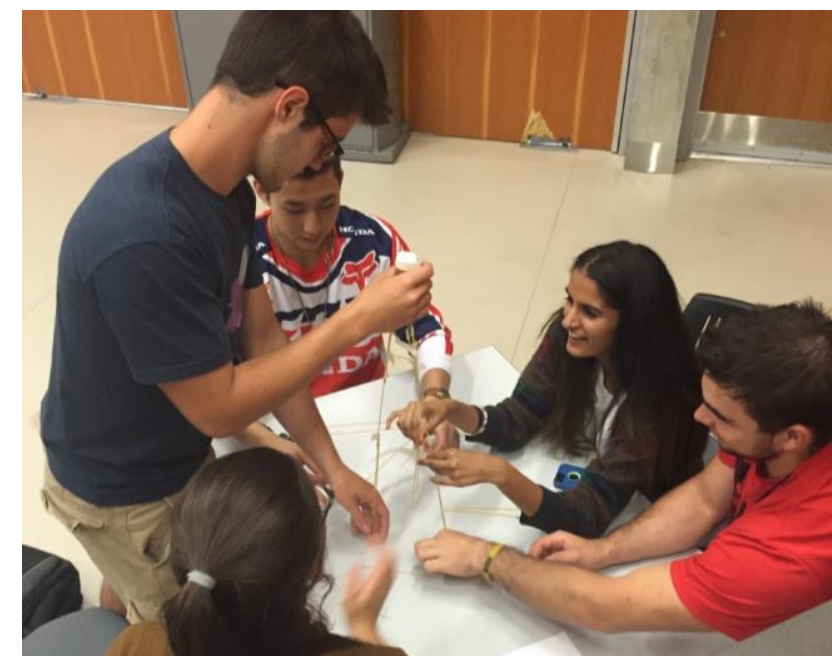

Figure 3. Students working on Marshmallow Challenge.

\subsection{Design Thinking Exercise}

Good exercise to introduce engineering students to customer interview process and discuss a role of empathy in design. Works best for a relatively simple product (e.g., a wallet); originally developed at Stanford's D-School [8].

In this exercise students work in pairs and take turns as either a designer who interviews a customer, or a customer responding to designer's questions. The process can be completed in 45-50 mins if no prototyping is involved; otherwise 90 mins is more appropriate.

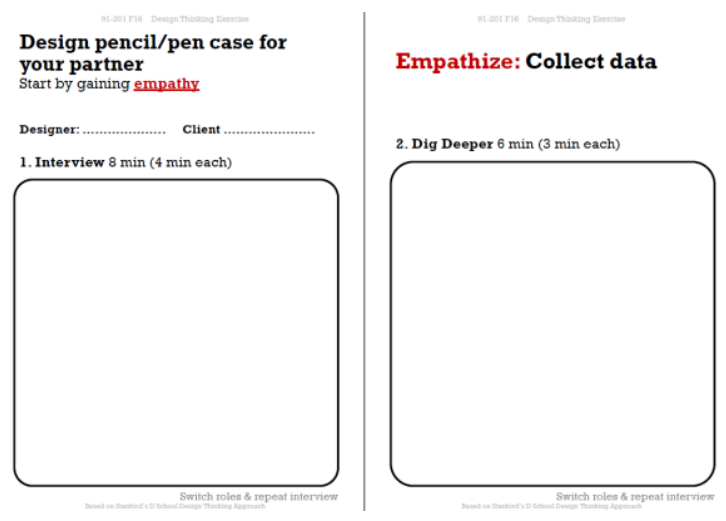

Fig. 4. Interview form for Design Thinking exercise.

The interview sheets provide well-flowing structure and consecutive, timed steps:

- Two-stage data collection

- Framing and re-framing the problem

- Defining problem statement

- Ideation (generating alternatives)

- Sharing solutions, and

- Feedback 


\section{SUMMARY}

Understanding and practicing creative techniques is increasingly important in engineering profession. The best results can obtained when students apply that knowledge consciously (e.g., via metacognition). A great wealth of creative methods is already available, but instructors have to be particular in choosing those that both fit in the available classroom time as well as contribute to development of creative skills of the students.

\section{References}

[1] De Graf, J., Lawrence, K. A. Creativity at Work: Developing the Right Practices to Make Innovation Happen, Jossey-Bass, 2002, 226 pp.

[2] Hargrove, R., "Fostering creativity in the design studio: A framework towards effective pedagogical practices," Art, Design \& Communication in Higher Education 10: 1, pp. 731, doi: 10.1386/adch.10.1.7_1

[3] Isaksen, S., Dorval, K.B., Treffinger D, (2010) Creative approaches to problem solving. 3rd ed. Thousand Oaks, 294 pp.

[4] Kelly, T., Kelly, D. Creative Confidence: Unleashing the creative potential within us all. New York: Crown Business, 2013, 288 pp.
[5] Martin, R. L. The opposable mind: how successful leaders win through integrative thinking. Boston, Mass, Harvard Business School Press, 2007

[6] Miron-Spektor, E.; Gino, F, Argote, Linda, "Paradoxical frames and creative sparks: "Enhancing individual creativity through conflict and integration," Organizational Behaviour and Human Decision Processes, 2011, vol.116 (2), pp.229240

[7] Sans de Acedo Lizarraga, M.L., Sanz de Acedo Baquedano, M.T, (2013), "How creative potential is related to metacognition," European Journal of Education and Psychology, vol. 6, no. 2 pp. 69-81.

[8] The Wallet Project, https://dschoolold.stanford.edu/groups/designresources/wiki/4dbb2/t he_wallet_project.html

[9] Wujec, T. Marshmallow Challenge, https://www.tomwujec.com/designprojects/marshmallow-challenge/ 